\title{
Does pre-angiography Total ST-segment resolution reliably predict spontaneous reperfusion of the infarct-related artery in patients with acute myocardial infarction?
}

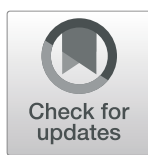

Zongsheng Guo and Xinchun Yang ${ }^{*}$ (D)

\begin{abstract}
Background: ST resolution (STR) after AMI is a non-invasive indicator of IRA reperfusion. We investigated whether pre-angiography STR predicted spontaneous IRA reperfusion in STEMI patients.

Method: Patients with STEMI undergoing primary PCI were recruited. Standard 12-lead ECG tracings were recorded at first medical contact, immediately prior to arterial puncture and $60 \mathrm{~min}$ after PCI. STR was classified as total ( $\geq 70 \%$; group I), partial ( $\geq 30$ and $<70 \%$; group II) or none (<30\%; group III). Patients were followed up for 1-year.

Results: The final analysis included 349 patients ( $n=77,160$ and 112 for groups I, II and III, respectively). Compared with groups I/II, pre-procedural TIMI flow in group III was less frequently grades 2 or $3(P<0.001)$. Pre-PCI STR $\geq 70 \%$ was an independent predictor of pre-PCI TIMI-3 flow (OR: 2.8; $P<0.001)$. Pre-PCI STR $<30 \%$ was independently associated with pre-PCI TIMI flow 0-2 (OR: 3.1; $P<0.001$ ). STR $=35.55 \%$ seems to be an optimal cut off for pre-procedural TIMI-3 flow prediction with sensitivity 0.943 , specificity 0.456 , Youden index $0.399, P=0.027$. STR prior to $P C I$ was inversely correlated with 1-year combined CV events rate. STR $>70 \%$ may predict a better clinical outcome.
\end{abstract}

Conclusions: Assessment of STR could potentially be used to stratify risk in patients with STEMI before PCI.

Keywords: ST elevation myocardial infarction, ST resolution, Reperfusion, Percutaneous coronary intervention, Cardiac mortality

\section{Background}

Reperfusion of the infarct-related artery (IRA) is a critical predictor of prognosis in patients with acute myocardial infarction (AMI) and may be evaluated either angiographically or non-invasively. Thrombolysis in myocardial infarction (TIMI) flow grade estimates epicardial flow by evaluating the flow of contrast material in epicardial coronary arteries during angiography [1]. Post-procedural TIMI flow of the IRA is used for risk stratification of patients with STEMI, [2, 3] but pre-procedural TIMI flow may also be an important predictor of clinical prognosis $[4,5]$. In an analysis of randomized trials, pre-procedural TIMI-3 flow was a more powerful prognostic predictor than TIMI-3 flow after angioplasty, [5] underscoring the

\footnotetext{
* Correspondence: xinchun_y@sina.com

Heart Center, Beijing Chaoyang Hospital, No. 8 workers' stadium south road, Chaoyang District, Beijing 100027, China
}

importance of early flow restoration in patients with STEMI.

The most common non-invasive method for evaluating reperfusion is to analyze the resolution of ischemic ST-segment changes in a series of ECG records. STsegment changes may be evaluated either as the sum of ST-segment deviations in all leads in a given infarction area or in the single lead with the largest ST deviation $[6,7]$. A quick estimation of maximal ST resolution (STR) as a surrogate marker of blood flow provides similar results to analysis of the sum of STR in all leads [8]. It was demonstrated that STR after PCI was a strong and independent predictor of cardiac mortality and recurrence of myocardial infarction (MI) across all spectra of clinical risk, $[6,7,9]$ and a lack of STR was even of prognostic value 6 years after the occurrence of AMI [10].

(c) The Author(s). 2019 Open Access This article is distributed under the terms of the Creative Commons Attribution 4.0 International License (http://creativecommons.org/licenses/by/4.0/), which permits unrestricted use, distribution, and reproduction in any medium, provided you give appropriate credit to the original author(s) and the source, provide a link to the Creative Commons license, and indicate if changes were made. The Creative Commons Public Domain Dedication waiver (http://creativecommons.org/publicdomain/zero/1.0/) applies to the data made available in this article, unless otherwise stated. 
Although pre-procedural TIMI flow is recognized to be a reliable predictor of cardiac mortality in patients with STEMI, the prognostic value of STR preceding primary PCI is still not well established. In this study, we evaluated whether pre-angiography STR reliably predicted spontaneous reperfusion of the IRA in patients with AMI undergoing primary PCI. Furthermore, we investigated whether pre-angiography STR was related to enzymatic infarct size or clinical prognosis.

\section{Methods}

\section{Study population}

From January 2015 to July 2017, we prospectively recruited 366 patients with STEMI using the following inclusion criteria: chest pain lasting $>30 \mathrm{~min}$; ST-segment elevation on the electrocardiogram (ECG) in $\geq 2$ adjacent leads $(\geq 0.2 \mathrm{mV}$ in leads $\mathrm{V} 1-3$ and $\geq 0.1 \mathrm{mV}$ in all other leads); the maximal levels of the enzymes, creatine kinasemuscle/brain (CK-MB) and cardiac troponin I (cTnI) were elevated to three times the upper limit of normal [11]; and referral for primary PCI was made within the first 6-12 h after symptom onset [12]. The exclusion criteria were: primary PCI of the left main coronary artery, left bundle branch block, accelerated idioventricular rhythm, ventricular fibrillation or paced rhythm before the procedure (these patients were excluded due to the distinctive ECG pattern observed in such cases); hemodynamic instability before the procedure; previous AMI; previous coronary artery bypass graft (CABG); and refusal to participate in the study. The diagnosis was made and medication, angiography and PCI performed by experienced cardiologists. The study complied with the Declaration of Helsinki. The ethics committee of Beijing Chao-Yang Hospital approved the study protocol, and written informed consent was obtained from each patient.

\section{Medication and $\mathrm{PCl}$}

All patients received an oral loading dose of clopidogrel $(600 \mathrm{mg})$ and aspirin (300 mg) immediately after confirmation of STEMI. A bolus of unfractionated heparin $(100 \mathrm{IU} / \mathrm{kg})$ was given intravenously before the procedure. Use of a platelet glycoprotein IIb/IIIa inhibitor before PCI was at the discretion of the interventional cardiologist; if administered, the heparin dose was reduced to $70 \mathrm{IU} / \mathrm{kg}$. PCI was carried out in all patients using a standard method [12]. Other medications used after PCI were given in accordance with current STEMI guidelines [12] and included clopidogrel $(75 \mathrm{mg} / \mathrm{d})$ and aspirin $(100 \mathrm{mg} / \mathrm{d})$ indefinitely.

The initial laboratory findings, physical examination findings, coronary risk factors, Killip class and left ventricular ejection fraction on echocardiography were acquired by protocol at admission. Total ischemic time (the time from symptom onset to first balloon inflation) was recorded in all patients.

CK-MB and CTnI levels were tested on admission and at $0,6,12$ and $24 \mathrm{~h}$ after PCI. The peak values of CK$\mathrm{MB}$ and $\mathrm{cTnI}$ were used as criteria to evaluate enzymatic infarct size [13]. Two-dimensional echocardiography to evaluate left ventricular function was performed on admission and prior to discharge. The 30-day, 6-month and 1-year follow-up was performed by outpatient visit or telephone interview. All-cause death, cardiac death and major cardiovascular (CV) events (including myocardial infarction, revascularization [PCI or CABG], stroke, heart failure and cardiac death) were recorded at each follow-up visit.

\section{Evaluation of electrocardiographic findings}

Standard 12-lead ECG tracings (paper speed, $25 \mathrm{~mm} / \mathrm{s}$; amplification, $10 \mathrm{~mm} / \mathrm{mV}$ ) were recorded at three occasions: 1) at first medical contact when STEMI was confirmed and pharmacologic intervention was initiated (on admission or in the ambulance); 2) immediately prior to arterial puncture; and 3) $60 \mathrm{~min}$ after PCI. ECG data were evaluated independently by two ECG technicians (each with $>5$ years of experience), who were blinded to each other's analyses and to the clinical characteristics and coronary angiography findings of the patients. STsegment deviations were calculated for all ECG traces by the two technicians and averaged.

ST-segments were measured at the J point relative to the preceding TP segment (isoelectric line). ST elevation was considered if it was $\geq 0.25 \mathrm{mV}$ in men aged $<40$ years, $\geq 0.2$ $\mathrm{mV}$ in men aged $>40$ years, or $\geq 0.15 \mathrm{mV}$ in women in leads V2 and V3 and/or $\geq 0.1 \mathrm{mV}$ in other leads, in accordance with current guidelines [12]. The summed STsegment deviation was calculated by adding the STsegment elevations in all infarct-related leads and STsegment depressions in all reciprocal leads $[6,14]$. For anterior infarction, the sum of the ST-segment elevations in leads V1 to V6, I and aVL was added to the sum of the STsegment depressions in leads II, III and aVF. For inferior infarction, the sum of the ST-segment elevations in leads II, III and aVF (and I, aVL, V5 and V6 if present) was added to the sum of the ST-segment depressions in leads V1 to V4. Pre-PCI STR was classified as total (resolution of the initial ST-segment elevation by $\geq 70 \%$ ), partial ( $\geq 30$ and $<$ $70 \%)$ or none $(<30 \%)[8]$.

\section{Analysis of angiographic findings}

Coronary angiography was performed in all patients. Qualitative and quantitative analyses were made independently by two cardiologists (each with $>8$ years of experience), who were blinded to the clinical and ECG characteristics; any inconsistencies were resolved by discussion. The culprit artery, or infarct related artery (IRA) was identified 
according to the presence of thrombus, total occlusion, or delayed anterograde flow. The flow of the IRA prior to and after PCI was graded as TIMI grade 0 (no perfusion), 1 (penetration without perfusion), 2 (partial perfusion) or 3 (complete perfusion) according to the Thrombolysis in Myocardial Infarction (TIMI) flow classification [15]. Successful PCI was defined as post-procedural TIMI-3 flow in the IRA, with a residual stenosis $\leq 20 \%$, and absence of clear dissection, thrombus or perforation within the revascularized vessel.

The primary study objective was to evaluate whether pre-angiography STR was predictive of spontaneous reperfusion of the IRA in patients with STEMI undergoing primary PCI. Secondary objectives were to determine whether pre-angiography STR was related to enzymatic infarct size (assessed from the peak cTnI level) or clinical prognosis (assessed from the in-hospital cardiac mortality, 1-year cardiac mortality and the incidence of combined major cardiovascular events including myocardial infarction, revascularization [PCI or CABG], stroke, heart and failure and cardiac death).

\section{Statistical analysis}

All analyses were performed using SPSS 20.0 (IBM Corp., Armonk, NY, USA). Normally distributed, continuous variables are expressed as means \pm standard deviations (SDs) and were compared using ANOVA analysis. Categorical variables are expressed as absolute and relative frequencies. and were compared using the chi-squared test. To identify whether pre-procedural STR predicted IRA patency, logistic regression analysis was performed after adjustment for differences in baseline characteristics; odds ratios (ORs) and $95 \%$ confidence intervals $(95 \% \mathrm{CIs})$ were calculated. We evaluated the diagnostic performance of STR at cutoffs of 30 and $70 \%$. An optimal cutoff was expected to have a sensitivity of at least $90 \%$. Correlations between variables were evaluated using Spearman's correlation coefficients (rS). Survival during follow-up was evaluated by the Kaplan-Meier method and log-rank test. A two-tailed Pvalue $<0.05$ was considered statistically significant.

\section{Results}

\section{Patient characteristics}

Between January 2015 and July 2017, 366 of 833 patients with STEMI undergoing primary PCI in our department fulfilled the inclusion criteria and were enrolled in our study. Eight patients underwent primary PCI of the left main coronary artery and were excluded due to the distinctive ECG pattern and prognosis. A further 9 patients failed PCI or underwent CABG and were also excluded due to the distinctive prognosis in such cases. Therefore, a total of 349 patients (257 male and 92 female) were included in the analysis of the pre-/post-procedural ECG, angiography data and follow-up information. Follow-up data at 1 year were obtained from 335 (98\%) of the 342 patients who were discharged from hospital alive.

Patients were divided into 3 groups based on preangiography STR: group I (STR $\geq 70 \%), n=77$ (22\%); group II $(30 \% \leq$ STR<70\%), $n=160$ (46\%); and group III (STR < $30 \%), n=112$ (32\%). The baseline and procedural characteristics of the study cohort are presented in Table 1 . Except for a higher percentage of patients with diabetes mellitus in group III $(P=0.03)$, the patients were comparable between groups with respect to age, gender, risk factors, blood pressure, heart rate, infarct localization, stent implantation, discharge medication and general characteristics of the diseased vessels.

\section{Myocardial perfusion}

Peak values of cTnI and CK-MB (used as indicators of enzymatic infarct size) [13] were significantly higher in group III than in the other groups (cTnI, $P<0.001$; CK-MB, $P<$ 0.01; Table 1). Prior to PCI, TIMI-0 flow in the IRA was observed more frequently in group III than in groups I and II $(P<0.001)$, while TIMI-2 and TIMI-3 flow were observed more often in groups I and II than in group III $(P<0.001$; Table 1, Fig. 1). The interval from symptom onset to balloon dilation did not differ significantly between groups.

Correlation analysis indicated that STR prior to PCI was inversely correlated with impaired TIMI flow (grade 0-2) at initial angiography $(\mathrm{rS}=-0.513, P<0.05)$, peak cTnI value $(\mathrm{rS}=-0.484, P<0.01)$ and peak $\mathrm{CK}-\mathrm{MB}$ value $(\mathrm{rS}=$ - 0.526; $P<0.01)$. Logistic regression identified complete STR (> 70\%) prior to emergency angiography as an independent predictor of pre-procedural TIMI-3 flow (OR: 2.8; 95\%CI: $1.3-4.8 ; P<0.001)$, while non-STR $(<30 \%)$ prior to emergency angiography was independently associated with impaired pre-procedural perfusion (TIMI flow 0-2) (OR: 3.1 ; 95\%CI: $1.9-5.0 ; P<0.001$ ). ROC curve indicated STR $=35.55 \%$ an optimal cut off for pre-procedural TIMI-3 flow prediction with sensitivity 0.943, specificity 0.456 , Youden index $0.399, P=0.027$, It seems more effective than $70 \%$ and $30 \%$ as a prediction of TIMI-3 flow (Sensitivity 0.995, specificity 0.414 , Youden index 0.368 for STR $=30 \%$; Sensitivity 0.445 , specificity 0.858 , Youden index 0.313 for STR =70\%;) (Fig. 2, Table 2).

Stent implantation was comparable among the three groups (Table 1), although the proportion of patients treated with platelet glycoprotein IIb/IIIa inhibitors was higher in group III than in the other groups $(P=0.03)$. Successful recovery of TIMI-3 flow after PCI was less frequent in group III than in groups I and II ( $P=0.03$; Table 1 , Fig. 1$)$. Patients in groups I and II had a higher left ventricular ejection fraction before discharge than patients in group III $(P=0.02)$.

\section{Clinical outcome}

Overall in-hospital cardiac mortality was $2.0 \%$ (2/160 in group II and 5/112 in group III, no in hospital death in 
Table 1 Clinical characteristics and outcomes stratified by ST resolution (STR)

\begin{tabular}{llll}
\hline Variable & STR $\geq 70 \%$ & $30 \% \leq S T R$ & STR $<30 \% \quad P$ \\
$n=77$ & $<70 \%$ & $n=112$ \\
& $(22 \%)$ & $n=160(46 \%)$ & $(32 \%)$
\end{tabular}

Patient characteristics

$\begin{array}{lllll}\text { Age (years) } & 61.2 \pm 7.3 & 62.1 \pm 8.4 & 60.0 \pm 7.8 & 0.12 \\ \text { Male (\%) } & 75.3 & 74.4 & 71.4 & 0.15 \\ \text { Smoking (\%) } & 55.8 & 52.5 & 58.0 & 0.26 \\ \begin{array}{l}\text { Hypercholesterolemia } \\ (\%)\end{array} & 41.6 & 37.5 & 40.2 & 0.54 \\ \begin{array}{l}\text { Diabetes mellitus (\%) } \\ \text { Renal insufficiency (\%) }\end{array} & 9.1 & 12.5 & 21.4 & 0.03 \\ \text { Previous infarction (\%) } & 6.5 & 5.6 & 8.0 & 0.09 \\ \text { Heart rate (bpm) } & 75.6 \pm 8.2 & 72.0 \pm 9.3 & 77.9 \pm 7.7 & 0.87 \\ \text { Killip class > 1 (\%) } & 11.4 \pm 3.2 & 15.8 \pm 3.8 & 19.4 \pm 4.6 & 0.08 \\ \text { Left ventricular ejection } & 56.6 \pm 7.9 & 52.0 \pm 8.2 & 42.4 \pm 7.6 & 0.02\end{array}$

fraction (\%)

Home medication (\%)

$\begin{array}{lllll}\text { Aspirin } & 21.3 & 24.1 & 22.6 & 0.12 \\ \text { Clopidogrel } & 6.2 & 5.7 & 5.2 & 0.64 \\ \text { Statins } & 16.4 & 17.7 & 15.7 & 0.55 \\ \beta \text { blockers } & 12.4 & 14.1 & 13.8 & 0.76 \\ \begin{array}{l}\text { ACE inhibitors/ATII } \\ \text { antagonists }\end{array} & 27.3 & 24.5 & 25.7 & 0.14\end{array}$

Ischemia characteristics

$\begin{array}{lllll}\begin{array}{l}\text { Total ischemic } \\ \text { time (min) }\end{array} & 445.6 \pm 46.2 & 481.7 \pm 48.4 & 473.0 \pm & 0.07 \\ \text { Anterior Ml (\%) } & 45.5 & 40.0 & 42.3 & 0.13 \\ \text { Non-anterior Ml (\%) } & 54.5 & 60.0 & 57.2 & 0.45 \\ \text { Maximal cTnl (ng/mL) } & 0.54 \pm 0.08 & 2.82 \pm 0.25 & 6.03 \pm & < \\ & & & 0.52 & 0.001 \\ \text { Creatine kinase-MB } & 54.0 \pm 6.3 & 168.0 \pm 14.4 & 276.0 \pm & < \\ \text { (U/L) } & & & 26.3 & 0.01 \\ \text { Multi vessel disease (\%) } & 35.0 & 32.5 & 33.9 & 0.41 \\ \text { nitial TIMl flow (\%) } & & & & \\ 0 & 14.3 & 36.3 & 80.4 & < \\ & & & & 0.001 \\ 1 & 7.8 & 9.4 & 6.3 & 0.45 \\ 2 & 26.0 & 26.9 & 9.8 & < \\ 3 & & & & 0.001 \\ & 51.9 & 27.5 & 3.5 & < \\ & & & & 0.001\end{array}$

Baseline Rentrop

classification (\%)

\begin{tabular}{|c|c|c|c|c|}
\hline $0-1$ & 62 & 66 & 59 & 0.23 \\
\hline $2-3$ & 38 & 34 & 41 & 0.26 \\
\hline \multicolumn{5}{|c|}{ reatment characteristics (\%) } \\
\hline Stent implantation & 93.5 & 95.6 & 95.5 & 0.54 \\
\hline atelet glycoprotein & 42.9 & 48.8 & 57.1 & 0.03 \\
\hline
\end{tabular}

Table 1 Clinical characteristics and outcomes stratified by ST resolution (STR) (Continued)

\begin{tabular}{cclll}
\hline Variable & $\begin{array}{l}\text { STR } \geq 70 \% \\
n=77 \\
(22 \%)\end{array}$ & $\begin{array}{l}30 \% \leq \text { STR } \\
<70 \%\end{array}$ & $\begin{array}{l}\text { STR }<30 \% \\
n=112\end{array}$ & $P$ \\
& $\begin{array}{llll}n=16 \%) \\
(32 \%)\end{array}$ & \\
\hline Post-procedural TIMI flow (\%) & & & \\
0 & 1.3 & 1.2 & 2.7 & 0.02 \\
1 & 1.3 & 4.4 & 8.0 & 0.01 \\
2 & 6.5 & 9.4 & 21.4 & 0.01 \\
3 & 90.9 & 85.0 & 67.9 & 0.03
\end{tabular}

Medical treatment

at discharge (\%)*

\begin{tabular}{lllll} 
Aspirin & 100 & 100 & 100 & 1 \\
Clopidogrel & 100 & 100 & 100 & 1 \\
Statins & 100 & 100 & 100 & 1 \\
B-blockers & 96.1 & 98.1 & 94.4 & 0.42 \\
$\begin{array}{l}\text { ACE inhibitor/ATII } \\
\text { antagonists }\end{array}$ & 64.9 & 59.5 & 65.4 & 0.56 \\
\hline
\end{tabular}

cTnl: cardiac troponin I; MI: myocardial infarction; STR: ST resolution; TIMI: thrombolysis in myocardial infarction. ${ }^{*}$ interval from symptom onset to balloon dilation. ACE: angiotensin converting enzyme; ATII: angiotensin receptor subtype II; CV: cardiovascular; STR: ST resolution; TIMI: thrombolysis in myocardial infarction

group 1). Medical therapy at discharge was comparable among groups. One-year follow-up data were not available for 7 discharged patients ( 3 in group III, 3 in group II and 1 in group I). There were additional 10 cardiac deaths ( 2 in group I, 3 in group II and 5 in group III) in the 1-year follow-up analysis. Cumulative 1-year cardiac mortality rate of all patients was $4.9 \%, 2.6 \%$ in group I, $3.1 \%$ in group II, and $8.9 \%$ in group III, Log Rank= 8.389. $P=0.015$ (Fig. 3); 82 out of 349 subjects (23.5\%) experienced at least one CV event, 11 in group I (14.3\%), 32 in group II $(20.0 \%)$ and 39 in group III $(34.8 \%), \log$ Rank $=8.389$. $\mathrm{P}=0.015$ (Fig. 4). Patients with better pre-

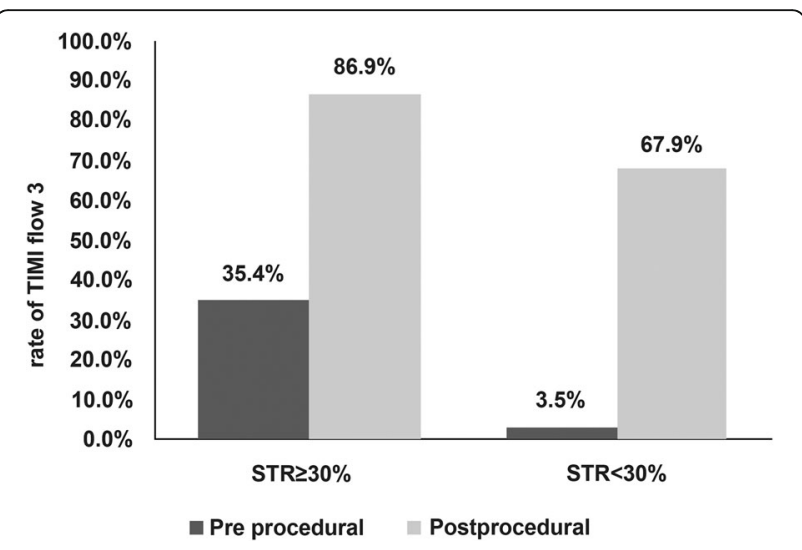

Fig. 1 Rates of TIMI-3 flow pre-percutaneous coronary intervention $(\mathrm{PCl})$ and post- $\mathrm{PCl}$ in patients with pre-procedural ST resolution $\geq 30$ and $<30 \%$ 


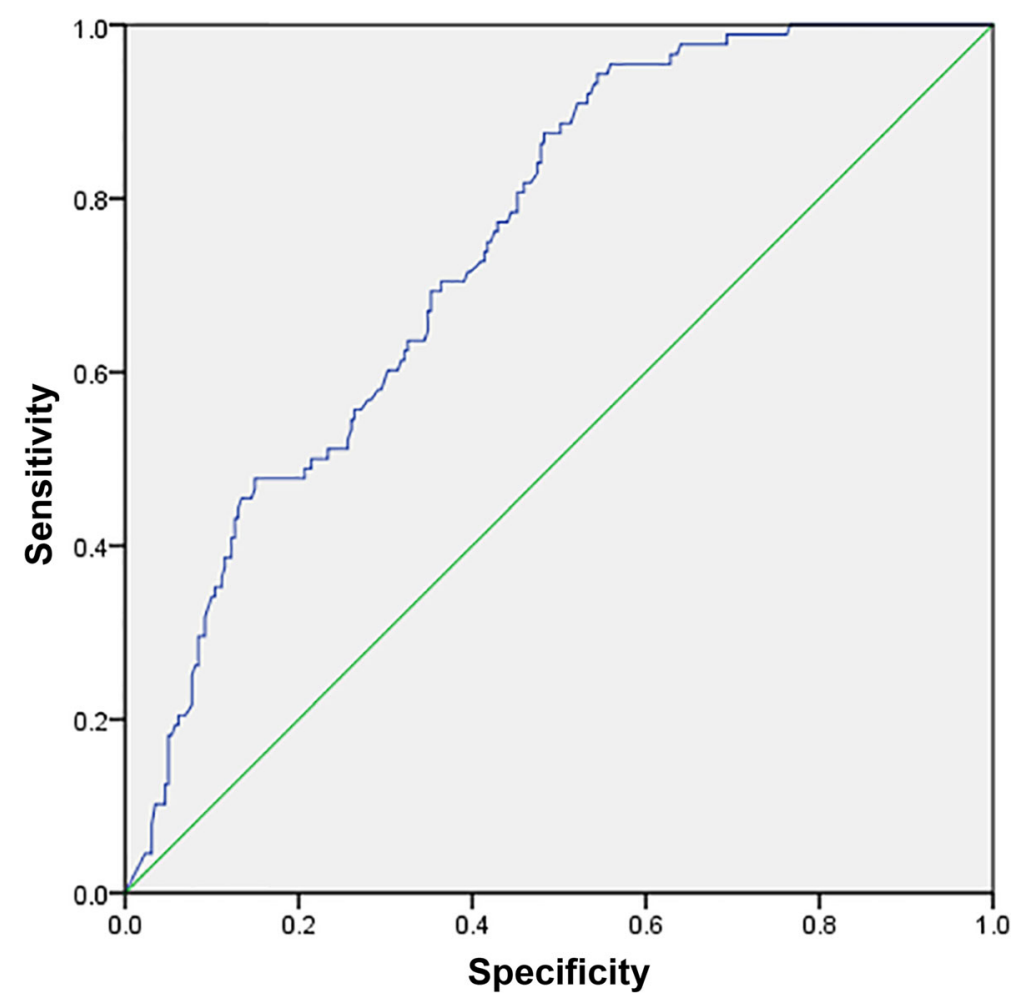

Fig. 2 Accuracy of STR to predict pre-procedural TIMI flow 3

PCI STR showed improved in-hospital survival, 1-year survival and event-free survival.

\section{Discussion}

Tissue perfusion may be assessed using angiography or electrocardiographic parameters (e.g. STR) [16, 17]. Both angiography and STR can be used to quantify the magnitude of myocardial reperfusion before or after thrombolysis and/or primary PCI. TIMI flow $\geq 2$ prior to thrombolysis or PCI is associated with a smaller enzymatic infarct size and better clinic prognosis independent of the time of reperfusion $[4,18]$. Although the relation of STR with enzymatic infarct size $[19,20]$ and cardiac mortality $[8,21]$ in patients treated with thrombolytic therapy has been demonstrated by clinical studies, the impact of pre-angiography STR on the prognosis of patients after primary PCI is still being investigated.

Our study investigated the value of pre-procedural ECG for predicting coronary reperfusion and clinical

Table 2 Accuracy of STR to predict pre-procedural TIMI flow 3

\begin{tabular}{lllll}
\hline STR & Sensitivity & Specificity & Youden index & $P$ value \\
\hline $30 \%$ & 0.955 & 0.414 & 0.368 & $>0.05$ \\
$70 \%$ & 0.455 & 0.858 & 0.313 & $>0.05$ \\
$35.55 \%$ & 0.943 & 0.456 & 0.399 & 0.027 \\
\hline
\end{tabular}

outcome. The average symptom onset-to-balloon time in our patients was $7.8 \mathrm{~h}$. STR prior to PCI was inversely correlated with impaired TIMI flow at initial angiography and with enzymatic infarct size (assessed from peak CTnI and CK-MB values).

Verouden and colleagues concluded that STR is a poor indicator of spontaneous reperfusion [22] and should not be used as a criterion to refrain from immediate coronary angiography in patients with STEMI. We partially agree with this viewpoint. When used as an indicator of spontaneous reperfusion, STR might be influenced by not only reperfusion of the IRA but also the collateral circulation, which could protect the threatened myocardium to some extent. In the absence of collateral flow, the myocardial area at risk (AAR) is the territory distal to the IRA. However, in the presence of collateral flow, the actual infarcted area would be the AAR minus the myocardium salvaged by collateral flow. The actual infarcted area is of great interest in studies evaluating the effectiveness of different reperfusion strategies and is a prognostic factor after STEMI [23, 24]. This concept might partially explain the discrepancy in the predictive accuracy of STR with regard to solo IRA reperfusion. STR reflects cardiac cell physiology and thus is a surrogate marker of blood flow. This might explain why STR probably underestimates the severity of IRA TIMI flow to some extend. In our study a certain cut off STR $<35.55 \%$ was an independent predictor 


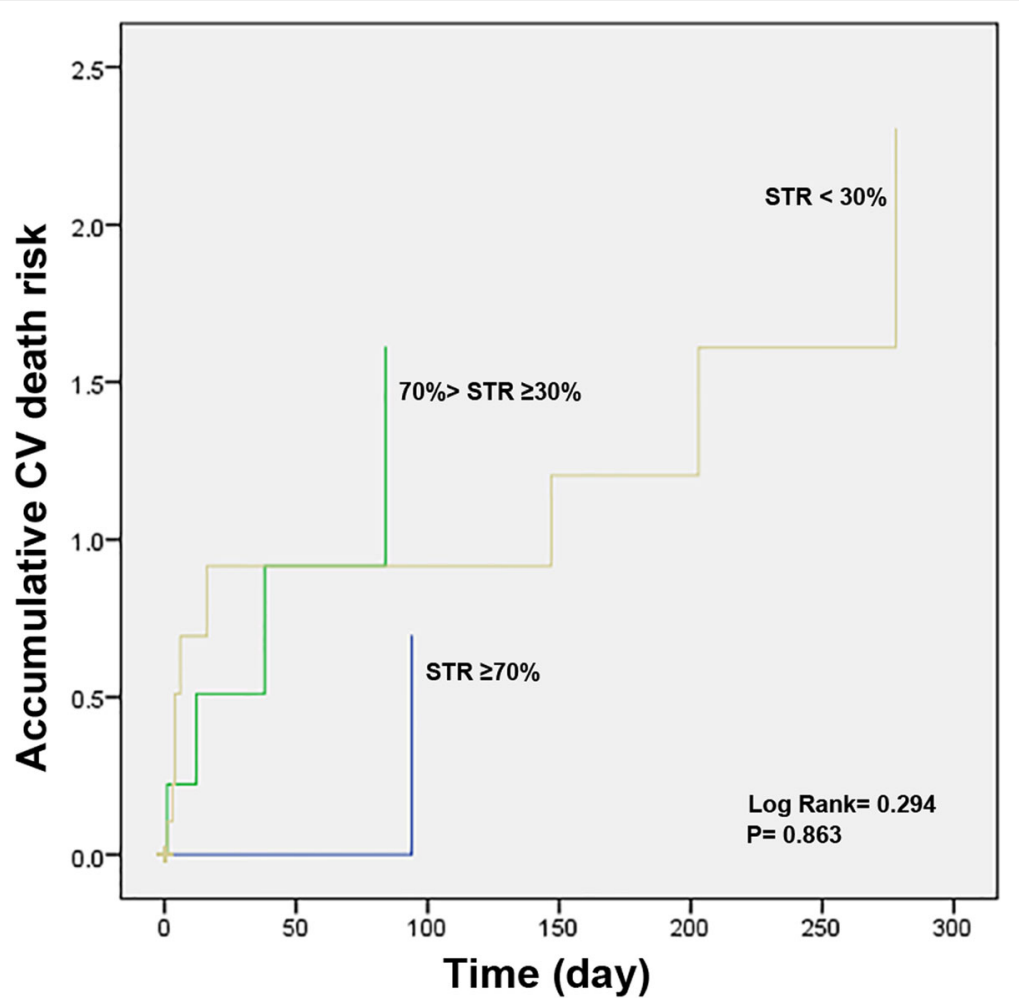

Fig. $3 \mathrm{CV}$ death risk of patients with different STR category (Kaplan-Meier curve)

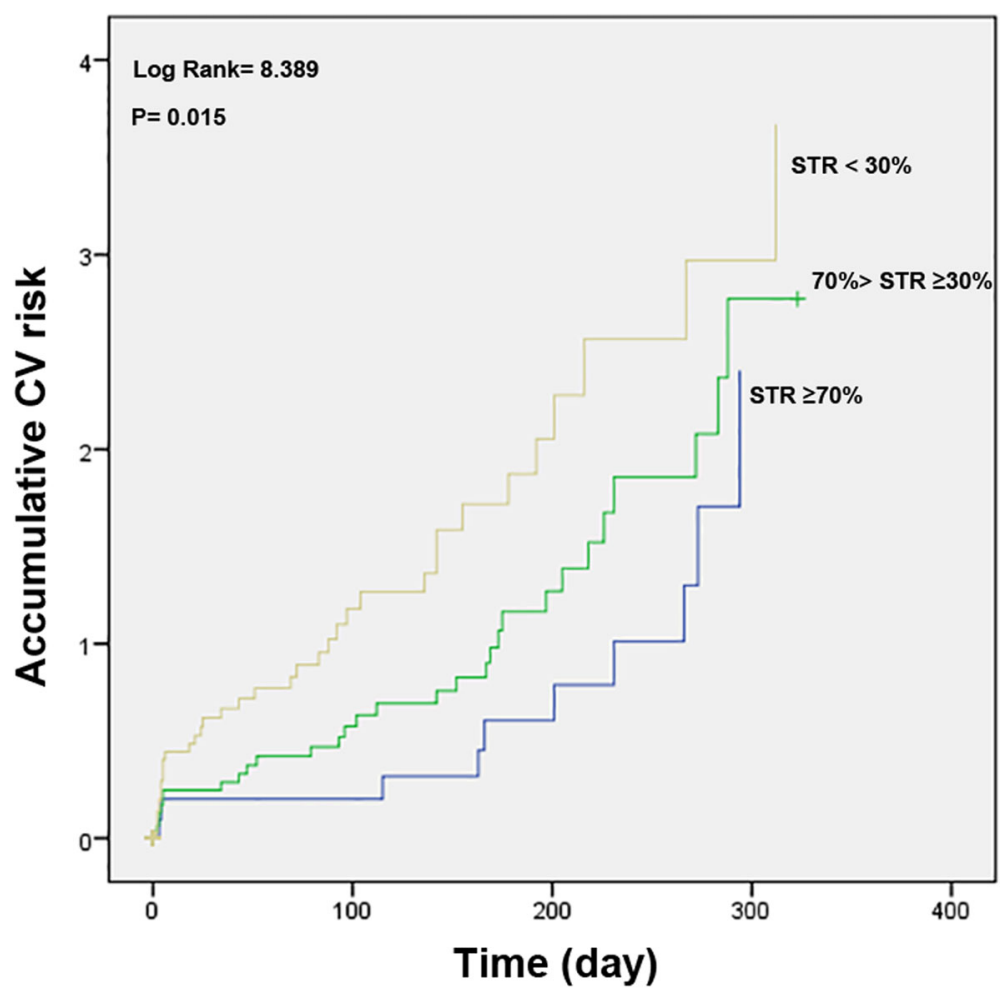

Fig. 4 CV risk of patients with different STR category (Kaplan-Meier curve) 
of impaired reperfusion (TIMI flow 0-2) with sensitivity 0.943 , specificity 0.456 , Youden index $0.399, P=0.027$. Although the summated ST elevation (sumSTE) at admission appears to be useful in the evaluation of AAR and hence prognosis, $[25,26]$ we agree with Verouden and colleagues that there is no evidence to support the use of STR as a criterion for not performing immediate coronary angiography in patients with STEMI.

Some investigators have proposed analyzing the residual absolute sumSTE rather than its relative change as a surrogate outcome measure $[6,27]$. Some researchers have documented the superiority of residual sumSTE over resSTE in the prediction of cardiac mortality [6,28]. In our study, STR prior to PCI was inversely correlated with 1 -year combined CV events rate. Furthermore, complete STR $(>70 \%)$ prior to emergency angiography may predict a better clinical outcome.

\section{Conclusions}

We demonstrated that complete STR prior to emergency angiography was an independent predictor of TIMI flow pre-PCI as well as 1-year cardiac mortality rate and 1-year CV events rate. Clinically, STR may imply reperfusion of the AAR by both the IRA and collateral flow. Our findings support STR as a simple and rapid measure to identify the risk level in patients before PCI. Patients with persistent ST elevation should be given more medical attention due to their high inhospital and 1-year cardiac mortality rates. Further studies should be carried out in a multi-institution setting with a large sample size to avoid selection bias. In addition, a standardized STR measurement should be developed to increase its reliability and repeatability.

\section{Abbreviations \\ AMI: Acute myocardial infarction; CABG: Coronary artery bypass graft; CK- MB: Creatine kinase-muscle/brain; IRA: Infarct-related artery; STR: ST resolution; TIMI: Thrombolysis in myocardial infarction}

\section{Acknowledgements}

Not applicable.

\section{Authors' contributions}

ZSG and XCY carried out the studies, participated in collecting data, drafted the manuscript, performed the statistical analysis and participated in its design. Both authors read and approved the final manuscript.

\section{Funding}

This work was supported by the Beijing Key Laboratory funding (2017GXYKFKT-03). The funders had no role in study design, data collection and analysis, decision to publish, or preparation of the manuscript.

\section{Availability of data and materials}

The datasets used and/or analysed during the current study are available from the corresponding author on reasonable request.

\section{Ethics approval and consent to participate}

The study complied with the Declaration of Helsinki. The ethics committee of Beijing Chao-Yang Hospital approved the study protocol, and written informed consent was obtained from each patient.
Consent for publication

Not applicable.

\section{Competing interests}

The authors declare that they have no competing interests.

Received: 16 January 2019 Accepted: 21 October 2019

Published online: 26 November 2019

\section{References}

1. Rind $E$, Arbel $Y$, Finkelstein A, Keren G, Banai S. Angiographic evaluation of epicardial and microvascular coronary flow. Isr Med Assoc J. 2009;11:173-7.

2. De Luca G, Suryapranata H, van't Hof AW, de Boer MJ, Hoorntje JC, Dambrink JH, et al. Prognostic assessment of patients with acute myocardial infarction treated with primary angioplasty: implications for early discharge. Circulation. 2004;109:2737-43.

3. Halkin A, Singh M, Nikolsky E, Grines CL, Tcheng JE, Garcia E, et al. Prediction of mortality after primary percutaneous coronary intervention for acute myocardial infarction: the CADILLAC risk score. J Am Coll Cardiol. 2005;45:1397-405

4. Brodie BR, Stuckey TD, Hansen C, Muncy D. Benefit of coronary reperfusion before intervention on outcomes after primary angioplasty for acute myocardial infarction. Am J Cardiol. 2000;85:13-8.

5. Stone GW, Cox D, Garcia E, Brodie BR, Morice MC, Griffin J, et al. Normal flow (TIMI-3) before mechanical reperfusion therapy is an independent determinant of survival in acute myocardial infarction: analysis from the primary angioplasty in myocardial infarction trials. Circulation. 2001;104:636-41.

6. McLaughlin MG, Stone GW, Aymong E, Gardner G, Mehran R, Lansky AJ, et al. Prognostic utility of comparative methods for assessment of ST-segment resolution after primary angioplasty for acute myocardial infarction: the controlled Abciximab and device investigation to lower late angioplasty complications (CADILLAC) trial. J Am Coll Cardiol. 2004:44:1215-23.

7. Buller CE, Fu Y, Mahaffey KW, Todaro TG, Adams P, Westerhout CM, et al. ST-segment recovery and outcome after primary percutaneous coronary intervention for ST-elevation myocardial infarction: insights from the assessment of Pexelizumab in acute myocardial infarction (APEX-AMI) trial. Circulation. 2008;118:1335-46.

8. Schroder R, Wegscheider K, Schroder K, Dissmann R, Meyer-Sabellek W. Extent of early ST segment elevation resolution: a strong predictor of outcome in patients with acute myocardial infarction and a sensitive measure to compare thrombolytic regimens. A substudy of the international joint efficacy comparison of Thrombolytics (INJECT) trial. J Am Coll Cardiol. 1995;26:1657-64.

9. Palmerini T, De Servi S, Politi A, Martinoni A, Musumeci G, Ettori F, et al. Prognostic implications of ST-segment elevation resolution in patients with STsegment elevation acute myocardial infarction treated with primary or facilitated percutaneous coronary intervention. Am J Cardiol. 2010;105:605-10.

10. Tomaszuk-Kazberuk A, Kozuch M, Bachorzewska-Gajewska H, Malyszko J, Dobrzycki S, Musial WJ. Does lack of ST-segment resolution still have prognostic value 6 years after an acute myocardial infarction treated with coronary intervention? Can J Cardiol. 2011:27:573-80.

11. Thygesen K, Alpert JS, White HD. Universal definition of myocardial infarction. Eur Heart J. 2007;28:2525-38.

12. Steg PG, James SK, Atar D, Badano LP, Blomstrom-Lundqvist C, Borger MA, et al. ESC guidelines for the management of acute myocardial infarction in patients presenting with ST-segment elevation. Eur Heart J. 2012;33:2569-619.

13. Ohlmann P, Monassier JP, Michotey MO, Berenger N, Jacquemin L, Laval G, et al. Troponin I concentrations following primary percutaneous coronary intervention predict large infarct size and left ventricular dysfunction in patients with ST-segment elevation acute myocardial infarction. Atherosclerosis. 2003;168:181-9.

14. De Luca G, Maas AC, Suryapranata H, Ottervanger JP, Hoorntje JC, Gosselink AT, et al. Prognostic significance of residual cumulative ST-segment deviation after mechanical reperfusion in patients with ST-segment elevation myocardial infarction. Am Heart J. 2005;150:1248-54.

15. Definitions used at TIMI trials. http://www.timi.org. Accessed August 1, 2008 Accessed.

16. Eitel I, Desch S, Sareban M, Fuernau G, Gutberlet M, Schuler G, et al. Prognostic significance and magnetic resonance imaging findings in aborted myocardial infarction after primary angioplasty. Am Heart J. 2009;158:806-13. 
17. van't Hof AW, Liem A, Suryapranata H, Hoorntje JC, de Boer MJ, Zijlstra F. Angiographic assessment of myocardial reperfusion in patients treated with primary angioplasty for acute myocardial infarction: myocardial blush grade. Zwolle Myocardial Infarction Study Group. Circulation. 1:97:2302-2306.

18. De Luca G, Suryapranata H, de Boer MJ, Ottervanger JP, Hoorntje JC, Gosselink AT, et al. Combination of electrocardiographic and angiographic markers of reperfusion in the prediction of infarct size in patients with STsegment elevation myocardial infarction undergoing successful primary angioplasty. Int J Cardiol. 2007;117:232-7.

19. Matetzky S, Freimark D, Chouraqui P, Novikov I, Agranat O, Rabinowitz B, et al. The distinction between coronary and myocardial reperfusion after thrombolytic therapy by clinical markers of reperfusion. J Am Coll Cardiol. 1998:32:1326-30.

20. Mauri F, Maggioni AP, Franzosi MG, de Vita C, Santoro E, Santoro L, et al. A simple electrocardiographic predictor of the outcome of patients with acute myocardial infarction treated with a thrombolytic agent. A Gruppo Italiano per lo studio della Sopravvivenza nell'Infarto Miocardico (GISSI-2)derived analysis. J Am Coll Cardiol. 1994;24:600-7.

21. Schroder R, Dissmann R, Bruggemann T, Wegscheider K, Linderer T, Tebbe $U$, et al. Extent of early ST segment elevation resolution: a simple but strong predictor of outcome in patients with acute myocardial infarction. J Am Coll Cardiol. 1994:24:384-91.

22. Verouden NJ, Haeck JD, Koch KT, Henriques JP, Baan J, van der Schaaf RJ, et al. ST-segment resolution prior to primary percutaneous coronary intervention is a poor indicator of coronary artery patency in patients with acute myocardial infarction. Ann Noninvasive Electrocardiol. 2010;15:107-15.

23. Murry $C E$, Jennings $R B$, Reimer KA. Preconditioning with ischemia: a delay of lethal cell injury in ischemic myocardium. Circulation. 1986;74:1124-36.

24. Yellon DM, Downey JM. Preconditioning the myocardium: from cellular physiology to clinical cardiology. Physiol Rev. 2003;83:1113-51.

25. Aldrich HR, Wagner NB, Boswick J, Corsa AT, Jones MG, Grande P, et al. Use of initial ST-segment deviation for prediction of final electrocardiographic size of acute myocardial infarcts. Am J Cardiol. 1988;61:749-53.

26. Larose $E$, Rodes-Cabau J, Pibarot $P$, Rinfret $S$, Proulx $G$, Nguyen $C M$, et al. Predicting late myocardial recovery and outcomes in the early hours of STsegment elevation myocardial infarction traditional measures compared with microvascular obstruction, salvaged myocardium, and necrosis characteristics by cardiovascular magnetic resonance. J Am Coll Cardiol. 2010;55:2459-69.

27. Desmet WJ, Mesotten LV, Maes AF, Heidbuchel HP, Mortelmans LA, Van de Werf FJ. Relation between different methods for analysing ST segment deviation and infarct size as assessed by positron emission tomography. Heart. 2004;90:887-92.

28. Brodie BR, Stuckey TD, Hansen C, VerSteeg DS, Muncy DB, Moore S, et al. Relation between electrocardiographic ST-segment resolution and early and late outcomes after primary percutaneous coronary intervention for acute myocardial infarction. Am J Cardiol. 2005;95:343-8.

\section{Publisher's Note}

Springer Nature remains neutral with regard to jurisdictional claims in published maps and institutional affiliations.

\section{Ready to submit your research? Choose BMC and benefit from:}

- fast, convenient online submission

- thorough peer review by experienced researchers in your field

- rapid publication on acceptance

- support for research data, including large and complex data types

- gold Open Access which fosters wider collaboration and increased citations

- maximum visibility for your research: over $100 \mathrm{M}$ website views per year

At $\mathrm{BMC}$, research is always in progress.

Learn more biomedcentral.com/submissions 